\title{
Variation Among Phytophthora cinnamomi Isolates from Oak Forest Soils in the Eastern United States
}

J. E. Eggers, Hermiston Agricultural Research and Extension Center, Oregon State University Center, Hermiston 97838; Y. Balci, Department of Plant Science and Landscape Architecture, University of Maryland, College Park 20742; and W. L. MacDonald, Division of Plant and Soil Sciences; Davis College of Agriculture, Natural Resources and Design; West Virginia University, Morgantown 26506

\begin{abstract}
Eggers, J. E., Balci, Y., and MacDonald, W. L. 2012. Variation among Phytophthora cinnamomi isolates from oak forest soils in the eastern United States. Plant Dis. 96:1608-1614.

Phytophthora cinnamomi isolates from geographically diverse oak forest soils in the Mid-Atlantic regions were studied to determine the extent of genotypic, phenotypic, and pathogenic variation. Four microsatellite loci were targeted for genetic analysis. Phenotypic characteristics measured included sexual and asexual spore dimensions and colony growth rate and morphology. Red oak (Quercus rubra) logs were inoculated with selected isolates to determine relative pathogenicity. Microsatellite analysis showed that the genetic variability of $P$. cinnamomi isolates was low, with two predominant microsatellite fingerprint groups (MFG). Isolates in MFG1 (48\% of the total isolates examined) were characterized by DNA fragment lengths of 120 and 122 bp at locus d39, 169 and 170 bp at locus e16, and 254 and 255 bp

and 124 bp at locus d39, 161 and 163 bp at locus e16, and 247 and 248 bp at locus g13. Asexual and sexual spore dimensions varied greatly among isolates but were similar to previously published descriptions. Phenotypic differences were most pronounced when data were grouped by MFG; the most significant were colony morphology and growth rate. Neither characteristic was a reliable predictor of isolate genotype. Differences in growth rates of MFGs were observed, with MFG1 being less tolerant at higher incubation temperatures. No variation in pathogenicity was observed on red oak logs. The low level of phenotypic and genotypic variation of $P$. cinnamomi suggest that other factors such as climate might play a more important role in its northern distribution and the diseases it causes.
\end{abstract} at locus g13. MFG2 isolates were characterized by marker sizes of 122
Numerous studies have been undertaken in Europe to investigate the role played by species of Phytophthora in forest health and their involvement in oak decline $(4,5,10,13,25,27,39)$. In these studies, diverse populations of Phytophthora spp. were found and correlations between the presence of Phytophthora spp. and the occurrence of oak decline were demonstrated in some oak forests. Similarly, an oak forest soil survey initiated in 2004 investigated whether Phytophthora spp. are present in north-central and northeastern U.S. oak forests and if correlations could be made between crown condition and the presence of Phytophthora spp. (2). This effort resulted in the isolation of seven Phytophthora spp., with Phytophthora cinnamomi being the most frequent species isolated (69\% of 171 sites) (2). Most oak species appeared healthy despite the presence of the pathogen in soil. A significant correlation between the presence of $P$. cinnamomi and the decline status was found with white oak (Quercus alba L.) but not with the other oak species.

Despite the well-known ability of $P$. cinnamomi to cause significant damage to a wide variety of plants, including oak (40), the role played by $P$. cinnamomi in eastern forests and, particularly, oak decline remains enigmatic and has received limited attention. The epidemiology of $P$. cinnamomi in the northeastern United States appears to be different. Although no obvious aboveground infections such as "bleeding cankers" have been observed on oak trees in the areas surveyed, root systems, particularly fine roots, were affected $(2,3)$. When belowground parts of white oak were

Corresponding author: Y. Balci, E-mail: ybalci@umd.edu

* The $\boldsymbol{e}$-Xtra logo stands for "electronic extra" and indicates that a supplementary figure and a supplementary table appear in the online edition.

Accepted for publication 22 May 2012.

http://dx.doi.org/10.1094/PDIS-02-12-0140-RE

(C) 2012 The American Phytopathological Society examined, $P$. cinnamomi was found to be causing significant fine root mortality and, thus, may be a contributing factor that triggered the widespread white oak decline in southern Ohio $(6,31)$. The impact of $P$. cinnamomi was particularly noted at lower elevations, where the soil moisture content was higher.

To better understand the relationship between $P$. cinnamomi and oak forest health, knowledge of existing P. cinnamomi populations is necessary. The focus of this study was to evaluate phenotypic and genotypic variations of $P$. cinnamomi isolates representing the variety of oak forests in the Mid-Atlantic United States.

\section{Materials and Methods}

Isolates. $P$. cinnamomi isolates used in this study were collected by Balci et al. (2) from rhizosphere soil samples of oak trees in the Mid-Atlantic area. In total, 61 isolates were used for this study, including 10 from Indiana, 3 from Kentucky, 9 from Maryland, 3 from Missouri, 15 from Ohio, 2 from Pennsylvania, and 19 from West Virginia isolates. To minimize the risk of development of atypical morphology and the loss of pathogenicity, isolates were inoculated onto pepper fruit ('Banana pepper'; 17,22). An agar plug from the edge of an actively growing $P$. cinnamomi culture on V8 juice agar (V8A) medium was used as inoculum. Pepper fruit were washed with dish soap and water, surface sterilized by spraying them with $70 \%$ ethanol, and patted dry with paper towels. A 5by-10-mm rectangle was cut from the pepper approximately $5 \mathrm{~cm}$ from the stem and $5 \mathrm{~cm}$ from the tip of the pepper using a sterilized scalpel. A similar-size agar block taken from the margin of a 3- to 5-day-old P. cinnamomi colony growing on V8A was placed into the hole cut in the pepper. Inoculated pepper plants were incubated for 3 to 4 days in a moist chamber at room temperature. P. cinnamomi was recovered from the resulting necrotic tissue by plating on PARPNH selective medium (17) and incubated at room temperature. Single zoospore isolates (SZIs) were produced to ensure that each isolate had only one reproducible microsatellite fingerprint $(15,35)$.

DNA extraction and microsatellite polymerase chain reaction. Mycelium for DNA extraction was produced in $1.5-\mathrm{ml}$ 
Eppendorf microcentrifuge tubes with potato dextrose broth (Difco Laboratories, Detroit). After centrifuging, the mycelial pellets were collected and frozen at $-20^{\circ} \mathrm{C}$, vacuum freeze dried, and stored at $-20^{\circ} \mathrm{C}(30)$. To extract DNA, $500 \mu \mathrm{l}$ of cetyltrimethylammonium bromide extraction buffer $(100 \mathrm{mM}$ Tris- $\mathrm{HCl}[\mathrm{pH} 8.0], 1.4 \mathrm{mM}$ $\mathrm{NaCl}, 20 \mathrm{mM}$ EDTA, and 2\% [wt/vol] hexadecyltrimethylammonium bromide) was added to the $1.5-\mathrm{ml}$ microcentrifuge tubes containing freeze-dried mycelium, incubated at $65^{\circ} \mathrm{C}$, and pulverized periodically with a sterile plastic pestle. Chloroform $(500 \mu \mathrm{l})$ was added to the tube, mixed thoroughly, and centrifuged at 14,500 rpm for 5 min (38). A GeneClean Spin Kit (MP Biomedicals, Solon, $\mathrm{OH}$ ) then was used to purify the DNA from the supernatant following the instructions in the kit. The recovered DNA was stored in sterile distilled water at $-20^{\circ} \mathrm{C}$.

Fingerprints of each $P$. cinnamomi isolate were produced through amplification of four polymorphic microsatellite loci. For loci d39, g16, and g10, each has a different primer pair specific for that locus. Previously, locus g13 was analyzed with two primer pairs, g13f and g13r1 (g13 primer pair) and g13f and g13r4 (g13 primer pair); however, only the g13 (4) primer set was used and was sufficient for the present analysis (14). Primers d39 and g16 amplify AC microsatellite motifs while primers g10 and g13 amplify AG microsatellite motifs. Fluorescent labels were attached to the $5^{\prime}$ end of one of the primers in each primer set so that each locus was represented by a different color dye (Applied Biosystems, Foster City, CA). Primer sequences and label locations are listed in Table 1.

Reaction mixtures consisted of $3 \mu \mathrm{l}$ of DNA (approximately 20 ng of genomic DNA), $0.1 \mathrm{mM}$ dNTPs, $2 \mathrm{mM} \mathrm{MgCl} 2,0.1 \mu \mathrm{M}$ forward and reverse primers, $0.5 \mathrm{U}$ of GoTaq Flexi DNA polymerase (Promega Corporation, Madison, WI), and $1 \times$ reaction buffer in a $10-\mu \mathrm{l}$ volume. Polymerase chain reactions were carried out using a PTC-100 thermocycler (MJ Research, Waltham, MA) with a heated lid and a touchdown program of 1 cycle of $96^{\circ} \mathrm{C}$ for $2 \mathrm{~min}$; then, 1 amplification cycle of $96^{\circ} \mathrm{C}$ for $30 \mathrm{~s}, 66^{\circ} \mathrm{C}$ for $30 \mathrm{~s}$, and $72^{\circ} \mathrm{C}$ for $30 \mathrm{~s}$; followed by 5 cycles similar to the first amplification cycle, except that the annealing temperature was lowered $1{ }^{\circ} \mathrm{C}$ every cycle; then, 20 cycles of $96^{\circ} \mathrm{C}$ for $30 \mathrm{~s}, 60^{\circ} \mathrm{C}$ for $30 \mathrm{~s}$, and $72^{\circ} \mathrm{C}$ for $30 \mathrm{~s}$; and a final cycle of $72^{\circ} \mathrm{C}$ for $7 \mathrm{~min}(15)$. Microsatellite products were separated by capillary electrophoresis at The Pennsylvania State University Biotechnology Institute's Nucleic Acid Facility (University Park) using standard protocols. Electrophoresis results were analyzed using GeneMapper 4.0 (Applied Biosystems). Finally, isolates were assigned to DNA fingerprint groups based on length polymorphisms of microsatellite markers (28).

Morphological analysis. To distinguish phenotypic variations among the studied $P$. cinnamomi populations, characteristics of asexual (sporangia and chlamydospores) and sexual (oospores, oogonia, and antheridia) reproductive structures, colony growth pattern, and growth rate of each isolate were measured.

Sporangia were produced from 3- to 4-day-old isolates grown on V8A. In all, 10 5-mm-diameter agar plugs were taken from the colony margin and placed on a sterile 9-cm-diameter cellophane disc covering $15 \mathrm{ml}$ of V8A and incubated at $20^{\circ} \mathrm{C}$ until the colonies grew to form a solid mat of mycelium covering the cellophane. The mycelium-covered cellophane was transferred to a sterile petri dish containing $15 \mathrm{ml}$ of $5 \%$ clarified V8 broth $(50 \mathrm{ml}$ of V8 juice, $1 \mathrm{~g}$ of $\mathrm{CaCO}_{3}$ centrifuged at $1,500 \mathrm{rpm}$ for $5 \mathrm{~min}$, and $50 \mathrm{ml}$ of supernatant brought up to 1 liter by adding distilled water, after which the broth was sterilized). After incubation at $20^{\circ} \mathrm{C}$ for $24 \mathrm{~h}$, the V8 broth was removed from the dish and the mycelium was washed twice with $20 \mathrm{ml}$ of sterile mineral salt solution and incubated in $20 \mathrm{ml}$ of mineral salt solution at $20^{\circ} \mathrm{C}$ in light conditions (24). The mineral salt solution was prepared as described by Chen and Zentmyer (11). The length and width (in micrometers) of 50 randomly selected sporangia of each isolate were measured at $200 \times$ and used to calculate sporangia length/width ratios.

Chlamydospores were produced using a protocol similar to that used for sporangia, except that the final step involved distilled water instead of mineral salt solution $(23,24,34)$. The diameters of 50 chlamydospores per isolate were measured at $200 \times$.

All of the isolates were determined to be the A2 mating type (2). Therefore, production of oospores from these isolates was accomplished by pairing isolates with a known A1 mating type of $P$. cinnamomi. After the isolates were grown on V8A for 5 days, a 5mm-diameter agar plug was taken from the colony margin and placed near the margin of a $60 \mathrm{~mm}$ diameter petri dish containing $10 \%$ clarified V8A (cV8A) (100 ml of V8 juice, $2 \mathrm{~g}$ of $\mathrm{CaCO}_{3}$ centrifuged for $5 \mathrm{~min}$ at $1,500 \mathrm{rpm}$, and $100 \mathrm{ml}$ of supernatant brought up to 1 liter with distilled water and autoclaved after adding $20 \mathrm{~g}$ of agar). An agar plug from the margin of an A1 $P$. cinnamomi colony growing on V8A was placed directly across the petri dish from the isolate to be tested. Pairings were incubated at $20^{\circ} \mathrm{C}$ in the dark for 3 weeks or until sexual structures formed. Agar blocks taken from the area of mycelium closest to the test isolate were scanned at $\times 400$ magnification. The diameter of 25 oogonia and oospores as well as the width of 10 antheridia were measured for each isolate.

Colony growth rate was determined by growing each isolate on $5 \%$ cV8A (5\% clarified V8 juice with $20 \mathrm{~g}$ of agar per liter) at 20 , $24,28,32,34$, and $37^{\circ} \mathrm{C}$. Agar plugs ( $5 \mathrm{~mm}$ in diameter) taken from the margins of 5-day-old $P$. cinnamomi SZI colonies were transferred to petri dishes containing $15 \mathrm{ml}$ of cV8A and initially grown for $48 \mathrm{~h}$ before they are examined for growth-temperature relationship. Three replicates of each isolate were tested. The margin of the colony was traced with a fine-tip marker; colony diameter, excluding the initial $48 \mathrm{~h}$ of growth, was measured and divided by the incubation period to obtain daily growth (millimeters per day).

For comparison of colony morphology, SZIs were transferred from V8A cultures to $100-\mathrm{mm}$ petri dishes containing $15 \mathrm{ml}$ of PDA and incubated at $24^{\circ} \mathrm{C}$ for 10 days. Isolates were recorded as having either a rosaceous (rose flower like pattern) or stellate (like a star in form) colony pattern $(17,22)$.

Pathogenicity. Isolates were selected for pathogenicity testing based on microsatellite fingerprint grouping. The $P$. cinnamomi isolates grouped in two microsatellite fingerprint patterns. Isolates from each microsatellite group were chosen that encompassed distribution across the study area and host type. In all, 23 isolates were used in the pathogenicity test: 12 from microsatellite fingerprint group (MFG) 1 and 11 isolates from MFG2.

Relative pathogenicity of $P$. cinnamomi isolates was determined by inoculation of cut red oak logs using a protocol adapted from Brasier and Kirk (7) and Hansen et al. (20). Red oak logs were cut from live trees on 25 September 2007, $48 \mathrm{~h}$ before inoculation. The ends of the logs were sealed with paraffin wax to retain moisture. Logs were approximately $1 \mathrm{~m}$ in length and 9.75 to $20 \mathrm{~cm}$ in diameter, with an overall mean log diameter of $12.7 \mathrm{~cm}$.

Of the 23 P. cinnamomi isolates tested, 11 were selected arbitrarily for inoculation into each log. Therefore, each $\log$ was inoculated with 11 different $P$. cinnamomi isolates and each of the 23 isolates being tested was inoculated into at least 11 different logs. A flame-sterilized cork borer was used to punch 5-mm-diameter holes through the bark to the cambium of each log. Three sets of four holes were punched in each $\log$, with one set encircling the $\log$ at $20 \mathrm{~cm}$, the second at $50 \mathrm{~cm}$, and the third at $80 \mathrm{~cm}$ from one end of the log. Agar plugs $5 \mathrm{~mm}$ in diameter from isolates actively

Table 1. Primer sequences $5^{\prime}$ to $3^{\prime}$ and fluorescent labels of each primer set

\begin{tabular}{lll}
\hline Locus & $\begin{array}{c}\text { Primer } \\
\text { number }\end{array}$ & \multicolumn{1}{c}{ Primer sequences } \\
\hline $\mathrm{d} 39$ & Primer 1 & 6FAM-GAGAGGTCTTCAGCACGAATG \\
& Primer 2 & ACCACTTTGGTTCTCGCC \\
e16 & Primer 1 & VIC-AGATCTCGCACCTCCCTAAAG \\
& Primer 2 & AGGCAAGATTTCGTAGAAGGC \\
g10 & Primer 1 & PET-GAACTCCAGCTCCTCCTGC \\
& Primer 2 & AAGTTCCCATTTCGCAACAC \\
g13r4 & Primer 1 & NED-ATGAGCTCACACAAGGTCTCG \\
& Primer 2 & CTTAGGCGTCAAAGTGTCAGC \\
\hline
\end{tabular}


growing on V8A were randomly inserted into 11 of the holes in each log. V8A plugs were used as controls and inserted into the remaining hole in each log. The bark plugs were replaced and covered with moistened cotton wool. A $5-\mathrm{cm}^{2}$ piece of aluminum foil was placed over the cotton wool and secured with duct tape. Inoculated $\operatorname{logs}$ were incubated at $20^{\circ} \mathrm{C}$ for 4 weeks. After incubation, the outer bark of each log was removed with a wood chisel; the revealed lesions were outlined with a marker and traced onto paper. Lesion tracings were digitally scanned and the area of each lesion was measured using Adobe Photoshop (Adobe Systems Incorporated, San Jose, CA).

Statistical analysis. In this study, the "host" refers to the oak group of the tree from around which the soil was used to isolate $P$. cinnamomi, and is designated as either red or white. The oak species from which $P$. cinnamomi was isolated in the white oak group were $Q$. alba (white oak) and $Q$. prinus (chestnut oak) and the oak species in the red oak group were $Q$. rubra (northern red oak), $Q$. coccinea (scarlet oak), and $Q$. velutina (black oak).

Isolate geographic origin groups were formed with respect to the north-south distribution of isolates in the study area. The $40^{\circ} \mathrm{N}$ latitude appears to be the northern boundary for $P$. cinnamomi in eastern U.S. oak forests (2). Therefore, isolate origin group 1 consisted of isolates from sites between $37^{\circ}$ and $39^{\circ} \mathrm{N}$ latitude and isolate origin group 2 isolates were from $39^{\circ} \mathrm{N}$ latitude and above.

Isolate spore characteristics, colony pattern, and growth rate data were grouped based on microsatellite fingerprint pattern, host oak type, isolate geographic origin, and colony morphology. In each grouping, morphological characteristics such as sporangia length, width, length/width ratio, chlamydospore diameter, oogonia diameter, oospore diameter, and antheridia width were compared. Mean colony growth rates at $20,24,28$, and $32^{\circ} \mathrm{C}$ of isolate groups also were compared. Growth rates were $\log$ transformed to achieve a normal distribution. The mean differences of each isolate group were tested using analysis of variance (ANOVA) and Tukey-Kramer honestly significant difference (HSD) comparison.

A hierarchical cluster analysis was performed using Ward's Method with the following variables: mean sporangia length, width, and length/width ratio; mean chlamydospore diameter; mean oogonium and oospore diameter; mean antheridia width; colony morphology; and mean growth rate at $20,24,28$, and $32^{\circ} \mathrm{C}$ (22). Isolates in each phenotypic cluster were analyzed with respect to DNA fingerprint pattern, colony morphology, oak types, and geographic origin. Fishers Exact Test was used to analyze microsatellite fingerprint, colony morphology, host oak type, and geographic origin characteristics of the isolates in one phenotypic cluster compared with isolates grouped together in other clusters.

Lesion areas were log transformed to achieve normal distribution and then tested using ANOVA and Tukey-Kramer HSD based on microsatellite fingerprint groups, isolate geographic origin groups, and host oak type groups. Fishers Exact Test was used to analyze the interaction of microsatellite fingerprint, colony morphology, host oak type, and isolate geographic origin groups. An $\alpha$ level of 0.05 was used for all statistical tests. Statistical analysis was performed with JMP 5.0 (SAS Institute Inc., Cary, NC).

\section{Results}

Microsatellite fingerprints. Analysis of the four microsatellite loci showed that the $61 \mathrm{P}$. cinnamomi isolates could be grouped into two MFGs (Supplementary Table S1; Table 2) Isolates from each group were distinguished from one another using three of the four microsatellite loci (Table 3). MFG1 was characterized by marker sizes of 120 and $122 \mathrm{bp}$ at locus d39, 169 and $171 \mathrm{bp}$ at locus e16, and 254 and 255 bp at locus g13 (Table 3). The most common fragment lengths at the g10 locus for MFG1 were 117 and $120 \mathrm{bp}$, followed by 119 and $120 \mathrm{bp}$, and, lastly, 117, 119, and $120 \mathrm{bp}$. Locus g10 showed variable fragment lengths, although there was some fragment length specificity for each group (Table 3). MFG2 was characterized by marker sizes of 122 and $124 \mathrm{bp}$ at locus d39, 161 and $163 \mathrm{bp}$ at locus e16, and 247 and $248 \mathrm{bp}$ at locus g13. Isolates in MFG2 had an even greater fragment length variability at the g10 locus than MFG1 isolates. The most frequently observed fragments were 115 and $117 \mathrm{bp}$ in length. Not all isolates from each group had the exact same fingerprint at loci $\mathrm{d} 39$, e16, and g13. Some isolates contained extra fragments or

Table 2. Number of isolates (total $=61$ ) from each DNA fingerprint group, colony morphology, and phenotypic cluster group when grouped by microsatellite fingerprint, colony morphology, host oak type, and isolate geographic origin

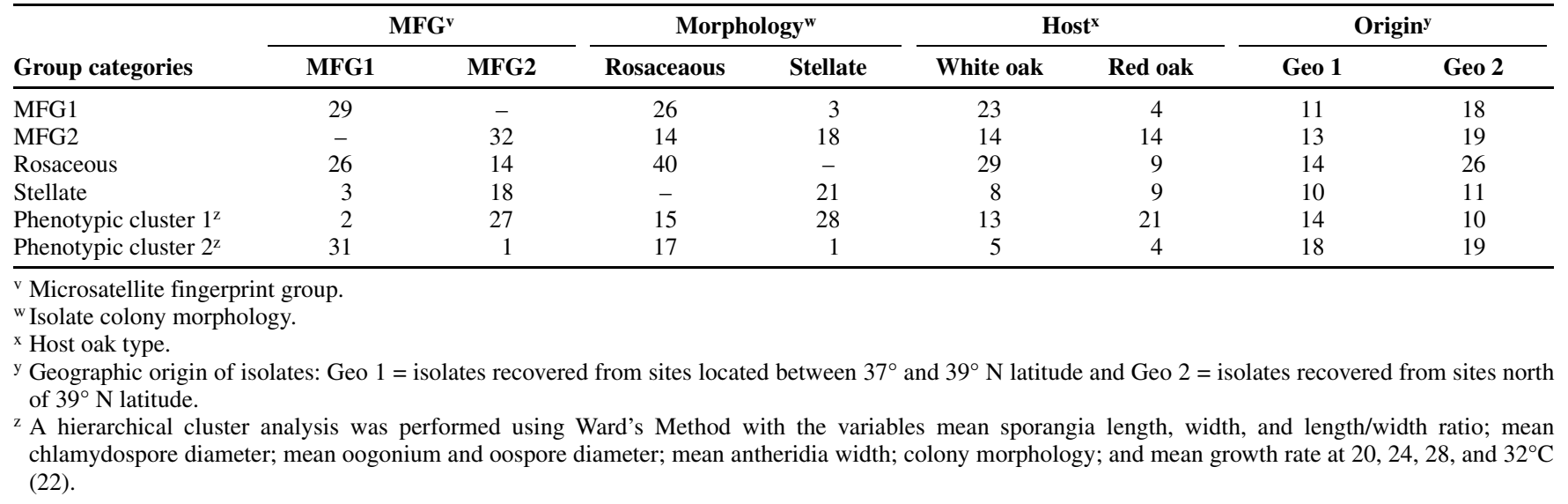

Table 3. Most commonly observed allele sizes at microsatellite loci d39, e16, and g10 of Phytophthora cinnamomi isolates from Australia, Papua New Guinea, and the mid-Atlantic United States

\begin{tabular}{llccc}
\hline & & \multicolumn{2}{c}{ Common DNA fragment lengths of microsatellite locus alleles (nucleotides) } \\
\cline { 3 - 4 } Groups $^{\mathbf{z}}$ & \multicolumn{1}{c}{ Isolate origin } & Locus d39 & Locus e16 & Locus g10 \\
\hline MFG1 & United States & $120 / 122$ & $169 / 171$ & $117 / 120$ \\
MFG2 & United States & $122 / 124$ & $161 / 163$ & $115 / 117$ \\
A1 type 1 & Australia, Papua New Guinea & $120 / 124$ & $169 / 169$ & $116 / 118$ \\
A2 type 1 & Australia, Papua New Guinea & $122 / 136$ & $169 / 171$ & $118 / 154$ \\
A2 type 2 & Australia, Papua New Guinea & $126 / 162$ & 163 & $114 / 116$ \\
\hline
\end{tabular}

${ }^{\mathrm{z}}$ Microsatellite fingerprint groups (MFGs) = P. cinnamomi isolates from mid-Atlantic U.S. forest soils; A1 and A2 types as described by Dobrowolski et al. (15). 
fragments with different lengths at one locus but were similar at the other two loci. Only one isolate from Indiana and one isolate from Maryland were in MFG1, with the remainder from these states in MFG2. All Ohio and Kentucky isolates grouped in MFG1 and all Pennsylvania isolates grouped in MFG2. One of two Missouri isolates was in MFG1 while the other was in MFG2. Of 19 West Virginia isolates, 7 were in MFG1 and 12 were in MFG2. All but one of the isolates isolated from soil from the West Virginia University forest (isolate IDs WVE-UF or WV-UF) were in MFG2.

Colony morphology and asexual and sexual spore structures. Two colony morphologies were exhibited by the study isolates on PDA. The rosaceous morphology was the most common (Fig. 1; Table 2).

Variation in sporangia length, width, and length/width ratio was observed. However, little variation existed in diameters of chlamydospores, oogonia, and oospores and antheridia width among the $P$. cinnamomi isolates. Sporangia of all MFG1 isolates were significantly greater in length $(F[1,3098]=44.58, P<0.001)$ and width $(F[1,3098]=942.84, P<0.001)$ than those of MFG2 but the length/width ratios $(F[1,3098]=328.94, P<0.001)$ were significantly smaller (Table 4$)$. No significant differences among the diameters of chlamydospores $(F[1,3098]=1.69, P=0.19)$, oogonia $(F[1,1673]=0.05, P=0.82)$, or oospores $(F[1,1673]=0.003$, $P=0.95)$ or the width of antheridia $(F[1,734]=0.25, P=0.62)$ were found between the isolates in MFG1 and MFG2 (Table 4).

Isolate means organized by latitude of site origin showed that isolates obtained between the 37th and 39th latitude had significantly greater mean sporangia length $(F[1,3098]=84.88, P<$ $0.001)$, width $(F[1,3098]=33.37, P<0.001)$, and length $/$ width ratio $(F[1,3098]=31.82, P<0.001)$ as well as chlamydospore $(F$ $[1,3098]=21.26, P<0.001), \operatorname{oogonia}(F[1,1673]=36.99, P<$ $0.001)$, and oospore diameter $(F[1,1673]=36.64, P<0.001)($ Table 4) than isolates from above the 39th latitude. Antheridia width $(F[1,734]=1.48, P=0.22)$ did not differ between groups.

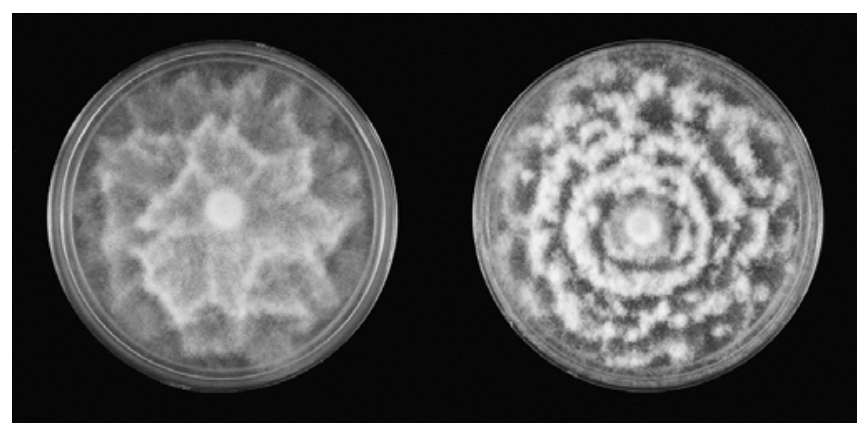

Fig. 1. Phytophthora cinnamomi isolate exhibiting stellate (left) and rosaceous (right) colony morphology on potato dextrose agar.
Mean sporangia length $(F[1,2948]=31.70, P<0.001)$, width $(F[1,2948]=136.87, P<0.001)$, and length/width ratio $(F$ $[1,2948]=15.14, P<0.001)$ and chlamydospore diameter $(F$ $[1,2948]=24.61, P<0.001)$ differed significantly between isolates from the rhizosphere of red versus white oak (Table 4). Mean $\operatorname{oogonium}(F[1,1598]=0.06, P=0.81)$ and oospore $(F[1,1598]=$ $0.01, P=0.91)$ diameter and antheridium width $(F[1,703]=1.87$, $P=0.17)$ did not differ significantly.

When spore characteristics of isolates were compared based on colony morphology, sporangia of isolates with a rosaceous colony pattern were slightly wider $(F[1,3098]=138.65, P<0.001)$. In contrast, isolates with a stellate colony appearance had a larger sporangium length/width ratio $(F[1,3098]=152.20, P<0.001)$ and chlamydospore diameter $(F[1,3098]=10.72, P<0.01)$ (Table 4). Sporangia length $(F[1,3098]=1.74, P=0.19)$, oogonia diameter $(F[1,1673]=1.16, P=0.28)$, oospore diameter $(F[1,1673]=$ $1.51, P=0.22)$, and antheridia width $(F[1,734]=1.47, P=0.23)$ did not differ significantly.

Colony growth rate. Colony growth rates varied among isolates (Table 5). Average growth rate was fastest at $20^{\circ} \mathrm{C}$ and slowest at $32^{\circ} \mathrm{C}$. No growth was observed for any isolate at 34 or $37^{\circ} \mathrm{C}$ (data not shown). When grouped by microsatellite fingerprints, MFG1 isolates had significantly greater growth rates at $20^{\circ} \mathrm{C}(F[1,181]=$ 14.26, $P<0.001)$ and $24^{\circ} \mathrm{C}(F[1,181]=158.29, P<0.001)$ than MFG2 isolates. Conversely, MFG2 isolates grew significantly faster at $28^{\circ} \mathrm{C}(F[1,181]=13.70, P<0.001)$ and $32^{\circ} \mathrm{C}(F[1,181]$ $=58.74, P<0.001)$ than MFG1 isolates (Table 5). Isolates from between the 37th and 39th latitude had significantly greater growth rates at $20^{\circ} \mathrm{C}(F[1,181]=7.76, P=0.006), 24^{\circ} \mathrm{C}(F[1,181]=$ $7.86, P=0.006)$, and $28^{\circ} \mathrm{C}(F[1,181]=7.03, P<0.01)$ than isolates from north of the 39 th parallel. There was no difference in growth rate at $32^{\circ} \mathrm{C}$ of isolate geographic origin groups (Table 5). Isolates from the rhizosphere of the different host groups showed no significant differences at any temperature tested. When growth rates of isolates with different colony morphologies were compared, isolates with a rosaceous colony pattern had significantly greater growth rates at $20^{\circ} \mathrm{C}(F[1,181]=9.78, P=0.002)$ and $24^{\circ} \mathrm{C}(F[1,181]=24.84, P<0.001)$ whereas stellate isolates had greater average growth rate at $32^{\circ} \mathrm{C}(F[1,181]=8.21, P=0.004)$. No significant difference were found at $28^{\circ} \mathrm{C}$ (Table 5).

Growth rate trends also were observed that varied across the microsatellite fingerprint and colony morphology groups. One trend was the difference in the change in growth rate from one incubation temperature to the next among isolate groups. Growth rates of MFG1 isolates decreased as incubation temperatures increased from 24 to $28^{\circ} \mathrm{C}$, whereas MFG2 growth rates stayed relatively the same (Table 5). This also was observed for isolates with different colony patterns. The rosaceous colonies had a mean reduction in diameter growth rate of $2.4 \mathrm{~mm} /$ day between 24 and $28^{\circ} \mathrm{C}$. The stellate colonies were much less affected and only had a mean

Table 4. Means and standard deviations of morphological characteristics of isolates grouped by microsatellite fingerprint pattern, geographic origin, host, and colony morphology

\begin{tabular}{|c|c|c|c|c|c|c|c|}
\hline Categories & $\begin{array}{c}\text { Sporangia } \\
\text { length }(\mu \mathrm{m})\end{array}$ & $\begin{array}{c}\text { Sporangia } \\
\text { width }(\mu \mathrm{m})\end{array}$ & $\begin{array}{c}\text { Sporangia } \\
\text { length/width } \\
\text { ratio }\end{array}$ & $\begin{array}{l}\text { Chlamydospore } \\
\text { diameter }(\mu \mathrm{m})\end{array}$ & $\begin{array}{c}\text { Oogonia } \\
\text { diameter }(\mu \mathrm{m})\end{array}$ & $\begin{array}{c}\text { Oospore } \\
\text { diameter }(\mu \mathrm{m})\end{array}$ & $\begin{array}{l}\text { Antheridia } \\
\text { width }(\mu \mathrm{m})\end{array}$ \\
\hline MFG1w & $68.3 \pm 13.5 \mathrm{a}$ & $41.8 \pm 6.0 \mathrm{a}$ & $1.6 \pm 0.2 \mathrm{a}$ & $45.6 \pm 7.2 \mathrm{a}$ & $40.6 \pm 3.9 \mathrm{a}$ & $36.8 \pm 3.8 \mathrm{a}$ & $17.4 \pm 2.3 \mathrm{a}$ \\
\hline MFG $2^{w}$ & $65.2 \pm 11.7 b$ & $36.2 \pm 4.1 \mathrm{~b}$ & $1.8 \pm 0.3 \mathrm{~b}$ & $45.3 \pm 6.0 \mathrm{a}$ & $40.6 \pm 4.3 \mathrm{a}$ & $36.8 \pm 3.9 \mathrm{a}$ & $17.3 \pm 2.5 \mathrm{a}$ \\
\hline Geo $1^{\mathrm{x}}$ & $69.2 \pm 12.7 \mathrm{a}$ & $39.6 \pm 6.1 \mathrm{a}$ & $1.8 \pm 0.3 \mathrm{a}$ & $46.5 \pm 5.9 \mathrm{a}$ & $41.3 \pm 4.1 \mathrm{a}$ & $37.4 \pm 4.0 \mathrm{a}$ & $17.4 \pm 2.5 \mathrm{a}$ \\
\hline Geo $2^{x}$ & $65.0 \pm 12.3 b$ & $38.4 \pm 5.5 b$ & $1.7 \pm 0.3 b$ & $45.0 \pm 7.0 \mathrm{~b}$ & $40.1 \pm 4.1 \mathrm{~b}$ & $36.3 \pm 3.7 b$ & $17.2 \pm 2.3 \mathrm{a}$ \\
\hline White oak ${ }^{\mathrm{y}}$ & $67.2 \pm 12.9 \mathrm{a}$ & $39.5 \pm 5.7 \mathrm{a}$ & $1.7 \pm 0.3 \mathrm{a}$ & $45.0 \pm 6.9 \mathrm{a}$ & $40.5 \pm 4.1 \mathrm{a}$ & $36.7 \pm 4.0 \mathrm{a}$ & $17.3 \pm 2.1 \mathrm{a}$ \\
\hline $\operatorname{Red~oak}^{\mathrm{y}}$ & $64.5 \pm 11.6 b$ & $37.0 \pm 5.1 \mathrm{~b}$ & $1.8 \pm 0.3 b$ & $46.3 \pm 6.1 b$ & $40.6 \pm 4.2 \mathrm{a}$ & $36.7 \pm 3.7 \mathrm{a}$ & $17.6 \pm 3.0 \mathrm{a}$ \\
\hline Rosaceous $^{\mathrm{z}}$ & $66.4 \pm 12.6 \mathrm{a}$ & $39.7 \pm 6.1 \mathrm{a}$ & $1.7 \pm 0.3 \mathrm{a}$ & $45.2 \pm 7.0 \mathrm{a}$ & $40.5 \pm 4.0 \mathrm{a}$ & $36.7 \pm 3.8 \mathrm{a}$ & $17.4 \pm 2.3 \mathrm{a}$ \\
\hline Stellate $\mathrm{z}$ & $67.1 \pm 12.8 \mathrm{a}$ & $37.1 \pm 4.6 b$ & $1.8 \pm 0.3 b$ & $46.0 \pm 5.5 b$ & $40.7 \pm 4.3 \mathrm{a}$ & $36.9 \pm 3.9 \mathrm{a}$ & $17.2 \pm 2.6 \mathrm{a}$ \\
\hline
\end{tabular}

${ }^{\mathrm{v}}$ Values within a group followed by the same letter are not significantly different (Tukey-Kramer honestly significant difference).

${ }^{\mathrm{w}}$ Microsatellite fingerprint group.

${ }^{x}$ Geographic origin of isolates: Geo $1=$ isolates recovered from sites located between $37^{\circ}$ and $39^{\circ} \mathrm{N}$ latitude and Geo $2=$ isolates recovered from sites north of $39^{\circ} \mathrm{N}$ latitude.

y Host oak type.

${ }^{\mathrm{z}}$ Isolate colony morphology. 
growth rate reduction of $0.5 \mathrm{~mm} /$ day between the 24 and $28^{\circ} \mathrm{C}$ incubation temperatures. At $32^{\circ} \mathrm{C}$, growth rates of both MFGs decreased but the growth rates of MFG1 isolates were more negatively affected than MFG2 isolates. This also was observed in isolates with different colony patterns, where the decrease in growth rate from 28 to $32^{\circ} \mathrm{C}$ was greater for isolates with the rosaceous colony pattern than for isolates with the stellate colony pattern. Additionally, the difference in mean diameter growth rate from the lowest to the highest incubation temperature was significantly greater $(P<0.0001)$ for MFG1 isolates $(13 \mathrm{~mm} /$ day $)$ than for MFG2 isolates ( $9 \mathrm{~mm} /$ day). The difference in mean diameter growth rate from the lowest to the highest incubation temperature was significantly greater $(P<0.0001)$ for isolates with rosaceous colony morphology $(12 \mathrm{~mm} /$ day $)$ than for isolates with stellate colony morphology ( $9 \mathrm{~mm} /$ day). These trends were not observed to occur in the other two isolate groups, where the isolates in each category of each isolate group behaved similarly with regards to growth rate. As incubation temperatures increased, growth rates of isolates in isolate geographic origin and host groups decreased.

Cluster analysis of phenotypic characteristics. A hierarchal cluster analysis was constructed using the variables of mean sporangia length, sporangia width, and sporangia length/width ratio; chlamydospore, oogonia, and oospore diameters; antheridia width; and growth rates on cV8A at $20,24,28$, and $32^{\circ} \mathrm{C}$ for each isolate (Supplementary Figure S1). The resulting groups corresponded closely to microsatellite DNA fingerprint groups. In all, 93\% of the isolates in MFG1 grouped in phenotype cluster two and $97 \%$ of the isolates in MFG2 grouped in phenotype cluster one (Table 2). Phenotype clusters and colony morphology also correlated. Of the isolates with a stellate colony pattern, $94 \%$ grouped in phenotype cluster 1 (Fisher's Exact Test, $P<0.001, R^{2}=0.25$ ). A significant relationship between isolate host oak type and phenotype cluster was measured. The majority of isolates from red oak rhizosphere soil (78\%) grouped in the phenotype cluster 1 and the remainder in cluster 2 . Conversely, $62 \%$ of the isolates from white oak soil grouped in phenotype cluster 1 and the remainder were in cluster 2 (Table 2). These correlations were significant based on a two-tailed Fisher's Exact Test $(P=0.009)$. The relationship between phenotype clusters and isolate geographic origin were not significant (Fisher's Exact Test $P=0.6$ ).

Relationship among groups defined by microsatellite fingerprint patterns, colony morphology, geographic origin, and host. When isolates were grouped based on colony morphology, isolates in the MFG1 more often formed rosaceous colonies (Fisher's Exact Test, $P=0.0002$; Table 2) and the majority of the stellate isolates were in MFG2 (Table 2). These relationships were significant (two-tailed Fisher's Exact Test $P=0.0002$ ).

Table 5. Mean colony diameter growth rates of isolates grouped by microsatellite fingerprint, isolate geographic origin, host oak type, and colony morphology

\begin{tabular}{|c|c|c|c|c|}
\hline \multirow[b]{2}{*}{ Categories } & \multicolumn{4}{|c|}{ Colony growth rate $(\mathrm{mm} / \mathrm{day})^{\mathrm{v}}$} \\
\hline & $20^{\circ} \mathrm{C}$ & $24^{\circ} \mathrm{C}$ & $28^{\circ} \mathrm{C}$ & $32^{\circ} \mathrm{C}$ \\
\hline MFG1 ${ }^{w}$ & $17.9 \pm 3.9 \mathrm{a}$ & $16.3 \pm 2.1 \mathrm{a}$ & $12.2 \pm 2.4 \mathrm{a}$ & $5.0 \pm 1.4 \mathrm{a}$ \\
\hline $\mathrm{MFG}^{\mathrm{w}}$ & $16.2 \pm 3.4 \mathrm{~b}$ & $12.9 \pm 1.4 \mathrm{~b}$ & $13.1 \pm 1.5 b$ & $6.9 \pm 1.8 b$ \\
\hline Geo $1^{x}$ & $18.0 \pm 4.7 \mathrm{a}$ & $15.2 \pm 2.8 \mathrm{a}$ & $13.2 \pm 2.2 \mathrm{a}$ & $6.2 \pm 1.9 \mathrm{a}$ \\
\hline Geo $2^{\mathrm{x}}$ & $16.4 \pm 2.7 \mathrm{~b}$ & $14.1 \pm 2.1 \mathrm{~b}$ & $12.4 \pm 1.9 \mathrm{~b}$ & $5.8 \pm 1.8 \mathrm{a}$ \\
\hline White oak ${ }^{y}$ & $17.0 \pm 4.4 \mathrm{a}$ & $14.2 \pm 2.2 \mathrm{a}$ & $13.5 \pm 2.1 \mathrm{a}$ & $6.4 \pm 1.6 \mathrm{a}$ \\
\hline Red oak ${ }^{y}$ & $16.8 \pm 3.6 \mathrm{a}$ & $14.6 \pm 2.3 \mathrm{a}$ & $12.0 \pm 1.7 \mathrm{a}$ & $6.1 \pm 1.9 \mathrm{a}$ \\
\hline Rosaceous $^{\mathrm{z}}$ & $17.6 \pm 3.8 \mathrm{a}$ & $15.1 \pm 2.5 \mathrm{a}$ & $12.7 \pm 2.3 \mathrm{a}$ & $5.7 \pm 1.9 \mathrm{a}$ \\
\hline Stellate ${ }^{\mathrm{z}}$ & $15.7 \pm 3.2 \mathrm{~b}$ & $13.2 \pm 1.5 b$ & $12.7 \pm 1.2 \mathrm{a}$ & $6.6 \pm 1.6 \mathrm{~b}$ \\
\hline
\end{tabular}

${ }^{v}$ Values within a group followed by the same letter are not significantly different (Tukey-Kramer honestly significant difference).

${ }^{\mathrm{w}}$ Microsatellite fingerprint group.

${ }^{\mathrm{x}}$ Geographic origin of isolates: Geo $1=$ isolates recovered from sites located between $37^{\circ}$ and $39^{\circ} \mathrm{N}$ latitude and Geo $2=$ isolates recovered from sites north of $39^{\circ} \mathrm{N}$ latitude.

${ }^{y}$ Host oak type.

${ }^{\mathrm{z}}$ Isolate colony morphology.
When colony morphology of isolates was compared across isolates from different oak types, a greater number of isolates from white oak rhizosphere soil were in MFG1 (Fisher's Exact Test, $P=$ 0.04 ) and most of the isolates from red oak rhizosphere soil were in MFG2 (two-tailed Fisher's Exact Test, $P=0.009$ ) (Table 2).

Both geographic origin groups were composed of nearly equal numbers of isolates from each MFG and no significant relationship was found (Table 2), although, a greater number of isolates from sites north of the 39th latitude formed rosaceous rather than stellate colonies.

Pathogenic variation. No significant difference was detected among lesion sizes of isolates tested (data not shown). All isolates except PA 1/6 and WVE-UF 5/3 produced significantly larger lesions on bark and cambial tissues of red oak logs than wounds inoculated with sterile agar plugs $(P<0.05)$. No significant difference was found when mean lesion areas of isolates were grouped based on microsatellite fingerprint $(P=0.99)$, isolate geographic origin $(P=0.94)$, host oak type $(P=0.24)$, or colony morphology $(P=0.91)$.

\section{Discussion}

The microsatellite markers developed by Dobrowolski et al. (15) can consistently differentiate genetic differences among $P$. cinnamomi populations, even those that are geographically distant from the populations used to develop the markers. Microsatellite analysis of U.S. P. cinnamomi isolates indicated low levels of genetic diversity among isolates collected from the study area. Isolates in this study were divided into two populations based on microsatellite fingerprint patterns, and the majority of isolates within each MFGs were identical at loci e16, g13, and d39. This low level of genetic diversity has been shown to occur in other P. cinnamomi populations worldwide $(9,15,16,29,30,32)$. The most extensive study of $P$. cinnamomi population genetics using the same molecular markers was conducted by Dobrowolski et al. (15). The authors showed that isolates from Australia also had very low levels of genetic diversity. The majority of A2 P. cinnamomi isolates in Australia could be divided into two groups using the same microsatellite markers which divided U.S. isolates into the two groups. Additionally, some of the allele fragment lengths are shared between the groups established by Dobrowolski and the U.S. MFGs. Genetic analysis of U.S. P. cinnamomi isolates from South Carolina using amplified fragments polymorphisms provided additional evidence of low genetic variability in P. cinnamomi from the United States (16).

Comparisons of microsatellite fingerprints of U.S. isolates to the fingerprints of $P$. cinnamomi isolates from Dobrowolski et al. (15) and Huberli et al. (22) indicated similarities in P. cinnamomi isolates from different continents (Table 3). Isolates of MFG1 were identical to the predominant fingerprint pattern of Dobrowolski's Australian A2 type 1 isolates at the e16 locus (169/171) and have the same marker size on one allele at locus d39 (122). The other d39 allele of the U.S. MFG1 isolates matches one allele at the d39 locus (120) of the Australian A1 type 1 P. cinnamomi isolates. Locus g10 of U.S. MFG1 isolates has markers not found in the three predominant genotypes identified by Dobrowolski et al. (15). The 120-bp marker consistently found in the U.S. MFG1 isolates also was present in an A1 P. cinnamomi isolate from the western United States included in the Dobrowolski et al. (15) analysis. The U.S. MFG2 isolates appear to have originated from a greater number of $P$. cinnamomi isolates characterized by Dobrowolski et al. (15). The markers at e16 of U.S. MFG2 (161/163) match those of the Australian A2 type 2 and markers found in P. cinnamomi isolates from Papua New Guinea. The d39 locus of U.S. MFG2 isolates matches markers found in both the d39 locus of Australian A1 type 1 isolates and the $\mathrm{d} 39$ locus of Australian A2 type 1 isolates (15). The markers of the g10 locus of MFG2 do not match any of the predominant genotypes found in Australia. The most frequent markers found in the U.S. isolates were 115 and $117 \mathrm{bp}$ in length. These markers could be the result of nucleotide deletion on both alleles at the g10 locus of the Australian P. cinnamomi A1 type 1 
(116 and 118) or nucleotide insertion on both alleles at the g10 locus of the Australian P. cinnamomi A2 type 2 (114 and 116).

The variations in phenotypic characteristics observed in the $P$. cinnamomi populations studied here were consistent with variations described by other researchers. Average sporangia size is somewhat larger than that first described by Rands (30) but other detailed descriptions have reported similar ranges and averages for sporangia length, width, and length/width ratio $(18,19,21,37)$. The largest sporangium recorded in this study appears to be the largest recorded for P. cinnamomi (14 $\mu \mathrm{m}$ longer and $15 \mu \mathrm{m}$ wider compared with the largest sporangia measured by Royle and Hickman; 37). Average chlamydospore diameter and range of variation among isolates in this study were slightly greater than those described by Rands (33). The dimensions of antheridia, oogonia, and oospores were within maximum and minimum measurement ranges and within the range of means described previously $(1,18,19,22,37)$. Likewise, colony morphology did not deviate greatly from previous descriptions $(22,40)$. Growth rates were slightly higher than reported by Huberli et al. (22) but were similar to that of the $P$. cinnamomi type culture (40).

Colony morphology of these U.S. P. cinnamomi isolates could not be predicted by genotype, host, or geographic origin, even though each MFG tended to exhibit one colony morphology more frequently than the other. Varying results on the linkage between genotype groups and colony morphology have been reported by others. Colony morphology of Australian P. cinnamomi isolates also grouped with a particular genotype (15). In contrast, colony morphology of Australian A2 type 1 isolates from a single site varied considerably (22). Environment may have contributed to this variation, because colony morphology of some isolates changed with incubation temperature. Despite some consistency of correlation between colony morphology and microsatellite fingerprint pattern, evidence also indicates that colony morphology of $P$. cinnamomi isolates depends on other factors, so that colony morphology alone is not diagnostic of genotype differences.

The relationship between isolate colony morphology and host was only evident with isolates associated with white oak rhizosphere soils. This result may be attributed, in part, to the grouping of these isolates in the MFG1 and predominant rosaceous colony pattern. Conversely, isolates from sites north of the 39th latitude grouped with similar frequency in each MFG but isolates from northern sites had a higher frequency of rosaceous colonies. Possibly, isolates with this colony morphology have a survivability advantage at lower temperatures, or they are more sensitive to higher temperatures. The latter hypothesis is supported by the fact that isolates with rosaceous colony patterns were less tolerant of temperature increases than isolates with stellate colony morphologies.

The P. cinnamomi isolates studied in this work varied phenotypically and genetically. However, the differences in microsatellite fingerprint pattern or phenotype of isolates do not appear to translate into pathogenic variation when inoculated to red oak logs. A similar finding was reported for the $P$. cinnamomi population isolated from oak forests in Spain and Portugal (9). Variation in pathogenicity of $P$. cinnamomi on other oak species and other tree genera has been reported, although the genetics of the isolates were not characterized $(12,26,35)$. Linde et al. (30) reported correlations between P. cinnamomi isolate multilocus isozyme genotypes and the level of pathogenicity in eucalyptus, suggesting that genotype variation may indicate pathogenic variability. Inoculation data from the present study, however, suggest that MFGs do not differ in pathogenicity. Additional pathogenicity tests on other P. cinnamomi hosts from different genera may differentiate pathogenicity among the different MFGs found in the United States. Balci et al. (3) showed that one P. cinnamomi isolate from eastern forest soils varied in pathogenicity when inoculated into the stems of four different oak species. An isolate from the same site was used in this study and it was found to belong to MFG2. Therefore, an isolate belonging to MFG1 may exhibit similar variation. Whether or not the variation would be consistent with that of MFG2 isolates is unknown. The different $P$. cinnamomi MFGs may even have simi- lar pathogenicities on oak but each fingerprint group may react differently to other known hosts. Knowing the pathogenicity of these MFGs on a wide range of $P$. cinnamomi hosts would be useful in developing plant cultivars resistant to $P$. cinnamomi. If different MFGs did turn out to have different pathogenicities on different hosts, the microsatellite markers would be useful in distinguishing which isolates were pathogenic on which hosts.

The presence of this fungus-like pathogen in ecosystems across the globe and the diversity of its hosts is testament to its versatility. This study has shown that the pathogenic versatility and cosmopolitan nature of $P$. cinnamomi arise from a rather discrete set of characteristics that have changed little despite its spread across the globe. Questions still remain about the impact of $P$. cinnamomi on health of northeastern U.S. forests and why P. cinnamomi is not having a greater impact on tree species known to be susceptible to infection. The extensive phenotypic evaluation would suggest that physical differences are small among $P$. cinnamomi isolates and the same can be said for genetic variation. This leads one to believe that other factors are influencing the ability of the P. cinnamomi populations in eastern forests to cause disease. One such factor could be climate. As previously stated, the northern limit of $P$. cinnamomi in the eastern United States is around $40^{\circ} \mathrm{N}$ latitude (2). Isolates were collected from regions with an average annual minimum temperature range of -12 to $-23^{\circ} \mathrm{C}$ (United States Department of Agriculture Plant Hardiness Zone). These low winter temperatures probably prevent a buildup of inoculum (8) or disease development due to short periods of optimum soil temperatures (e.g., $>15^{\circ} \mathrm{C}$ ) (36), which may be the reason why a greater disease impact is not seen. Even if natural stem infections were to occur, winter temperatures would slow the progression of the disease, possibly allowing the tree to overcome the infection. Balci et al. (3) demonstrated in field inoculation experiments that lesion development of stem-inoculated oak seedlings decreased when inoculated in the fall compared with spring inoculations. These are important considerations when looking to the future of these forests. Although P. cinnamomi was not observed causing aboveground infections in the northeast-central United States, decreased periods of temperatures that limit $P$. cinnamomi growth in the soil could result in increased $P$. cinnamomi inoculum, leading to more root infections. Warmer or shorter winters also could result in the progression of $P$. cinnamomi from the roots into the main stem of trees instead of being limited to the roots (2). Increasing temperatures could lead to an increased incidence of drought, thus weakening trees, leaving them more susceptible to P. cinnamomi infection (8). P. cinnamomi already has been linked to white oak decline in southern Ohio $(6,31)$ and could contribute to further decline, or outright disease could be more commonplace if warming trends continue.

\section{Literature Cited}

1. Ann, P. J., and Ko, W. H. 1985. Variants of Phytophthora cinnamomi extend the known limits of the species. Mycologia 77:946-950.

2. Balci, Y., Balci, S., Eggers, J., MacDonald, W. L., Juzwik, J., Long, R., and Gottschalk, K. W. 2007. Phytophthora species associated with forest soils in the eastern and north central U.S. oak ecosystems. Plant Dis. 91:705-710.

3. Balci, Y., Balci, S., MacDonald, W. L., and Gottschalk, K. W. 2008. Relative susceptibility of oaks to seven species of Phytophthora isolated from oak forest soils. For. Pathol. 38:394-409.

4. Balci, Y., and Halmschlager, E. 2003. Incidence of Phytophthora species in oak forests in Austria and their possible involvement in oak decline. For. Pathol. 33:157-174.

5. Balci, Y., and Halmschlager, E. 2003. Phytophthora species in oak ecosystems in Turkey and their association with declining oak trees. Plant Pathol. 52:694-702.

6. Balci, Y., Long, R. P., Mansfield, M., Balser, D., and MacDonald, W. L. 2010. Involvement of Phytophthora species in white oak (Q. alba) decline in southern Ohio. For. Pathol. 40:430-442.

7. Brasier, C. M., and Kirk, S. A. 2001. Comparative aggressiveness of standard and variant hybrid alder phytophthoras, Phytophthora cambivora and other Phytophthora species on bark of Alnus, Quercus and other woody hosts. Plant Pathol. 50:218-229.

8. Braiser, C. M., and Scott, J. K. 1994. European oak declines and global warming: a theoretical assessment with special reference to the activity of Phytophthora cinnamomi. EPPO Bull. 24:221-232. 
9. Caetano, P., Ávila, A., Sánchez, M.E., Trapero, A., and Coelho, A.C. 2009. Phytophthora cinnamomi populations on Quercus forests from Spain and Portugal. Pages 261-269 in: Proc. Fourth IUFRO Working Party Meeting on Phytophthoras in Forests and Natural Ecosystems. Monterey, CA. Gen. Tech. Rep. PSW-GTR-221.

10. Chavarriaga, D., William, J. A., Leifert, C. L., Belbahri, L., and Woodward, S. 2007. Phytophthora cinnamomi and other fine root pathogens in north temperate pine forests. FEMS Microbiol. Lett. 276:67-74.

11. Chen, D., and Zentmyer, G. A. 1970. Production of sporangia by Phytophthora cinnamomi in axenic culture. Mycologia 62:397-401.

12. Crandall, B. S., Gravatt, G. F., and Milburn Ryan, M. 1945. Root disease of Castanea species and some coniferous and broadleaf nursery stocks, caused by Phytophthora cinnamomi. Phytopathology 35:162-180.

13. Delatour, C. 2003. Phytophthoras and oaks in Europe. Phytophthora in forest and natural ecosystems. Pages 78-88 in: 2nd Int. IUFRO Working Party 7.02.09 Meeting, Albany, Western Australia. J. A. McComb, St. J. Hardy, G. E. Tommerup, and I. C. Murdoch, eds. University Print, Perth, Australia.

14. Dobrowolski, M. P., Tommerup, I. C., Blakeman, H. D., and O'Brien, P. A. 2002. Non-Mendelian inheritance revealed in a genetic analysis of sexual progeny of Phytophthora cinnamomi with microsatellite markers. Fungal Genet. Biol. 35:197-212.

15. Dobrowolski, M. P., Tommerup, I. C., Shearer, B. L., and O'Brien, P. A. 2003. Three clonal lineages of Phytophthora cinnamomi in Australia revealed by microsatellites. Phytopathology 93:695-704.

16. Duan, C.-H., Riley, M. B., and Jeffers, S. N. 2008. Characterization of Phytophthora cinnamomi populations from ornamental plants in South Carolina, USA. Arch. Phytopathol. Plant Prot. 41:14-30.

17. Erwin, D. C., and Ribeiro, O. K. 1996. Phytophthora cinnamomi Rands (1922) var. cinnamomi. Pages 269-280 in: Phytophthora Diseases Worldwide. American Phytopathological Society, St. Paul, MN.

18. Gallegly, M. E., and Hong, C. 2008. Phytophthora: Identifying Species by Morphology and DNA Fingerprints. American Phytopathological Society, St. Paul, MN.

19. Gerrettson-Cornel, L. 1983. A compendium of the morphology of Phytophthora cinnamomi Rands from Australia. Acta. Bot. Hung. 29:91-105.

20. Hansen, E. M., Parke, J. L., and Sutton, W. 2005. Susceptibility of Oregon forest trees and shrubs to Phytophthora ramorum: a comparison of artificial inoculation and natural infection. Plant Dis. 89:63-70.

21. Ho, H. H., and Zentmyer, G. A. 1977. Morphology of Phytophthora cinnamomi. Mycologia 69:701-713.

22. Huberli, D., Tommerup, I. C., Dobrowolski, M. P., Calver, M. C., and Hardy, G. E. St. J. 2001. Phenotypic variation in a clonal lineage of two Phytophthora cinnamomi populations from Western Australia. Mycol. Res. 105:1053-1064.

23. Huberli, D., Tommerup, I. C., and Hardy, G. E. St. J. 1997. The role of paragynous and amphigynous antheridia in sexual reproduction of Phy- tophthora cinnamomi. Mycol. Res. 101:1383-1388.

24. Hwang, S. C., Ko, W. H., and Aragaki, M. 1975. A simplified method for sporangial production by Phytophthora cinnamomi. Mycologia 67:1233-1234.

25. Jönsson, U., Jung, T., Sonesson, K., and Rosengren, U. 2005. Relationship between health of Quercus robur, occurrence of Phytophthora species and site conditions in southern Sweden. Plant Pathol. 54:502-511.

26. Jordan, A. P., and Tainter, A. P. Susceptibility of southern Appalachian oaks to Phytophthora cinnamomi. Castanea 61:348-355.

27. Jung, T., Blaschke, H., and Oßwald, W. 2000. Involvement of soilborne Phytophthora species in Central European oak decline and the effect of site factors on the disease. Plant Pathol. 49:706-718.

28. Lasker, B. A., and Ran, Y. 2004. Analysis of polymorphic microsatellite markers for typing Penicillium marneffei isolates. J. Clin. Microbiol. 42:1483-1490.

29. Linde, C., Drenth, A., Kemp, G. H. J., Wingfield, M. J., and von Broembsen, S. L. 1997. Population structure of Phytophthora cinnamomi in South Africa. Phytopathology 87:822-827.

30. Linde, C., Drenth, A., and Wingfield, M. J. 1999. Gene and genotypic diversity of Phytophthora cinnamomi in South Africa and Australia revealed by DNA polymorphisms. Eur. J. Plant Pathol. 105:667-680.

31. Nagle, A. M., Long, R. P., Madden, L. V., and Bonello, P. 2010. Association of Phytophthora cinnamomi with White Oak Decline in Southern Ohio. Plant Dis. 94:1026-034.

32. Old, K. M., Dudzinski, M. J., and Bell, J. C. 1988. Isozyme variability in field populations of Phytophthora cinnamomi in Australia. Aust. J. Bot 36:355-360.

33. Rands, R. D. 1922. Streepkanker van Kaneel, veroorzaakt door Phytophthora cinnamomi n. sp. (Stripe canker of cinnamon caused by Phytophthora cinnamomi n. sp.). Meded. Inst. Plantenziekten 54. (In Dutch)

34. Ribeiro, O. K. 1983. Physiology of asexual sporulation and spore germination in Phytophthora. Pages 55-70 in Phytophthora: Its Biology, Taxonomy, Ecology, and Pathology. D. C. Erwin, S. Bartnicki-Garcia, and P. H. Tsao, eds. American Phytopathological Society, St. Paul, MN.

35. Robin, C., and Desprez-Loustau, M.-L. 1998. Testing variability in pathogenicity of Phytophthora cinnamomi. Eur. J. Plant Pathol. 104:465-475.

36. Roth, L. F., and Kuhlman, E. G. 1966. Phytophthora cinnamomi, an unlikely threat to Douglas-fir forestry. For. Sci. 12:147-159.

37. Royal, D. J., and Hickman, C. J. 1964. Observations on Phytophthora cinnamomi. Can. J. Bot. 42:311-318.

38. Taylor, B., and Powell, A. 1982. Isolation of plant DNA and RNA. Focus 4:4-6

39. Vettraino, A. M., Morel, O., Perlerou, C., Robin, C., Diamandis, S., and Vannini, A. 2005. Occurrence and distribution of Phytophthora species in European chestnut stands, and their association with ink disease and crown decline. Eur. J. Plant Pathol. 111:169-180.

40. Zentmyer, G. A. 1980. Phytophthora cinnamomi and the Diseases It Causes. Monogr. No. 10. American Phytopathological Society, St. Paul, MN. 